\title{
Recreational fishing on the West coast of the Northern Adriatic Sea (Western Mediterranean) and its possible ecological implications
}

\author{
F. Pranovi*, M. Anelli Monti, A. Caccin, S. Colla, M. Zucchetta \\ Environmental Sciences, Informatics and Statistics Department, Ca' Foscari University of Venice, Campus Scientifico, via Torino 155, 30170, Venice, Italy
}

\section{H I G H L I G H T S}

- Marine recreational fishing on the West coast of the Northern Adriatic Sea was assessed.

- CPUE and annual catches have been assessed.

- For some species, annual catches resulted to be comparable or higher than commercial ones.

- Possible ecological effects have been analysed by using trophodynamic indicators.

- The need to consider MRF in the management planning was stressed.

\section{A R T I C L E I N F O}

\section{Article history:}

Received 18 September 2015

Received in revised form

26 November 2015

Accepted 27 November 2015

Available online 2 December 2015

\section{Keywords:}

Marine recreational fishing

CPUE

PPR

Lindex

Adriatic Sea

\begin{abstract}
A B S T R A C T
The marine recreational fishing (MRF) represents one of the most popular activities along the coasts of numerous countries around the world, in particular in the Mediterranean Sea. Despite the evidences of potential effects on the marine biodiversity and commercially exploited stocks, a sound information base and adequate management plans are still lacking, both at the national and basin level. An analysis of the MRF on the West coasts of the Adriatic Sea was carried out, in 2014, by using a standardized questionnaires approach, aiming to describe the state of the art and to preliminarily assess catches, in comparison with the commercial ones, at the regional scale. Gilt-headed seabream, European seabass, cuttlefish, squid and Atlantic bluefin tuna resulted the anglers' preferred species, even if the top five in term of caught biomass were bluefin tuna, seabream, cuttlefish, common dolphinfish and little tunny, in the order (accounting up to $60 \%$ of total catches). The exploitation level resulted to be significant, as confirmed by the comparison with commercial fisheries, being the MRF captures $30 \%$ or $45 \%$ of the artisanal fishery in the same area, with some species, such as bluefish, bonito, pandora and picarel, showing larger values. The preliminary assessment of ecological effects, highlighted that the exploitation use about $10 \%-16 \%$ of energy fixed by the primary production (Primary Production Required to sustain fishery), but the ecosystem effects are still sustainable (Lindex and probability to be sustainable fished). However, combining catches by MRF with those by small scale fishery completely changes the situation, showing an unsustainable condition, suggesting the need for taking into the account also MRF in the future management planning for the Adriatic coastal area.
\end{abstract}

(C) 2015 Elsevier B.V. All rights reserved.

\section{Introduction}

Worldwide, marine recreational fishing (MRF) is a high participation activity of large economic and social value (in Europe, it has been estimated to generate a total expenditure over 25 billion $€$ per year, Pawson et al. (2008)). As recreational fishing demonstrated to exert a potential impact on marine biodiversity and

\footnotetext{
* Corresponding author.

E-mail address: fpranovi@unive.it (F. Pranovi).
}

exploited stocks (Coleman et al., 2004; Lewin et al., 2006; Strehlow et al., 2012), and to be a source of conflict with commercial activities (Cooke and Cowx, 2006), in the last three decades it has gained an increasing scientific interest.

Recreational fishing has been described as one of the most popular leisure activities in the coastal areas of numerous countries around the world, particularly in the Mediterranean Sea (Sutinen and Johnston, 2003; Moutopoulos et al., 2013). Although MRF represents an expanding activity, a sound information base and adequate management plans are still lacking, both at the national and basin level (Gaudin and De Young, 2007; Lee and Chang, 2008). 
Such factors would contribute to guarantee economic, cultural, and social benefits and to protect the marine resources from overfishing and other negative impacts.

In Italy, for instance, data about the MRF is scattered and not homogeneous among different sources, in relation to both number of anglers and caught biomass (Cingolani et al., 1999; Romanelli and Fiori, 2013). The activity is regulated by law (max $5 \mathrm{~kg}$ per day per person, or one specimen if heavier), but it does not require a licence (as opposed to fresh and brackish waters); only tuna fishing needs a specific registered permission, since this species is subjected to TAC regulation (Silvestri, 2013). For these reasons, the regulation of recreational fisheries is difficult and often leads to conflicts between the commercial and recreational sectors.

Despite the fact that the Adriatic Sea represents one of the Mediterranean areas in which the MRF has a long tradition and showed a recent rapid growth (Gaudin and De Young, 2007), no real assessment has been performed recently. This is of particular importance when considering the need for an integrated management plan of the coastal area. As consequence of the recently (2010) implemented ban for the trawling fishery inside the three miles from the coast (having the effect to completely eliminate the local derogations in place until 2010; see Pranovi et al., 2015) indeed, along the Western coast of the Adriatic Sea only two commercial fisheries are allowed: the stripped venus clam (Chamelea gallina) mechanical harvesting (by hydraulic dredge) and the artisanal fishery (by static gear). Given the fact that also the MRF seems to concentrate in this area, in order to maximize the positive effects of this measure, a new approach that takes into the account all different activities dealing with the exploitation of renewable resources in the area, is needed (Pranovi et al., 2015).

Within this context, the paper aims to:

- estimate the resources exploitation rate by marine recreational fishing;

- compare results with the commercial fisheries data;

- assess possible ecological effects at the ecosystem level.

\section{Materials and methods}

\subsection{Survey methodology}

In order to characterize the recreational fishing activity on the northern Adriatic coasts, an interview campaign aimed at anglers was set up, using standardized questionnaires.

A preliminary phase of the research in 2013 was devoted to identify the biological, economic and social parameters to be included in the questionnaires, in order to estimate different aspects related to the complex phenomenon of the marine recreational fishing (MRF) along the Adriatic coast. The main questions regarded the fishing techniques, fishing grounds (inshore vs. offshore areas and relationships with the presence of submerged structures), preferences in terms of target species, catches, fishing effort (in terms of number of trip per week in the different seasons), cost per trip and possible interactions with the commercial fisheries. A first version of the protocol was then tested on a small group of anglers, by mean of face-to-face interviews. Subsequently, anglers were identified thanks to local associations, in particular FIPSAS (Italian Recreational Fishing and Underwater Activity Federation) and contacted by various means (directly meeting them, at the bait shops, straight at the quay, by e-mail), proposing them to compile the online questionnaire form. About 500 anglers, who lived on the Italian Northern Adriatic coast or visited it frequently have been contacted during 2014.

\subsection{Data analysis}

Based on collected data, the annual effort per angler (in terms of the number of trips per year) and the catch per unit effort (CPUE, in terms of kg per angler per trip) were estimated. Combining information for each target species, the average yearly catch was also estimated. The bootstrapping method was applied to estimate the 95\% confidence interval (Shao and Tu, 1996; Lehtonen and Pahkinen, 2004). According to the procedure, CPUE samples were randomly drawn from the database, repeating the process for 1000 times. Once built, the new dataset (composed by all targeted species) was used to estimate the confidence interval ( $\alpha=0.025)$.

To calculate total catches per year, two different sources for the number of anglers in the area were used: the Italian Recreational Fishing and Underwater Activity Federation (FIPSAS) and the Ministry (MIPAAF) that reported 1624 and 2633 anglers, respectively.

In order to compare MRF catches with the commercial fishery landings, official statistics for the region (MIPAAF, 2014) and data from the Chioggia fish market, the largest one in the Northern Adriatic Sea, were used.

\subsection{Trophodynamic indicators}

To investigate possible effects of the MRF exploitation on the marine ecosystem, two different trophodynamic indicators have been applied.

The Primary Production Required to sustain fishery (PPR) is a measure of the level of exploitation of the studied area (Pauly and Christensen, 1995), accounting for the fraction of Primary Production sequestrated by fisheries. The method is based on the trophic level of the caught species, the energy transfer efficiency between trophic levels, and on the primary productivity of the basin, combined as follow,

$P P R=\sum_{i=1}^{n} \frac{L_{i}}{C R}\left(\frac{1}{T E}\right)^{\left(T L_{i}-1\right)}$

with $L_{i}=$ landing of the $i$-species;

$C R=$ conversion rate of wet weight to carbon (fixed at 1:9, according to Pauly and Christensen, 1995);

$T E=$ transfer efficiency (fixed at $10.5 \%$, according to Libralato et al., 2015);

$T L=$ trophic level of $i$-species.

The PPR is commonly expressed as a percentage of the total primary production. Primary production for the NAS was estimated by using monthly chlorophyll-a data derived from MODIS satellite (http://neo.sci.gsfc.nasa.gov/), according to Behrenfeld and Falkowski (1997).

The Loss in Production Index (Lindex) allows assessing the effects of the loss in energy due to the exploitation as it propagates through the trophic web (Libralato et al., 2008; Coll et al., 2008).

The Lindex is defined as:

Lindex $=\frac{P P R T E^{T L c-1}}{P P \ln (T E)}$

where $P P R=$ Primary Production Required (see above);

$T E=$ transfer efficiency (fixed at $10.5 \%$, according to Libralato et al., 2015);

$T L C=$ mean trophic level of catches,

$P P=$ Primary Production (see above).

The method allows also estimating the probability that such energy loss is sustainable for the ecosystem on the basis of a nonlinear empirical relationship between the Lindex and the probability to be sustainably exploited (psust), according to the analyses carried out by Libralato et al. (2008).

\section{Results}

A total of 100 compiled questionnaires have been collected, with a return rate of $20 \%$. 


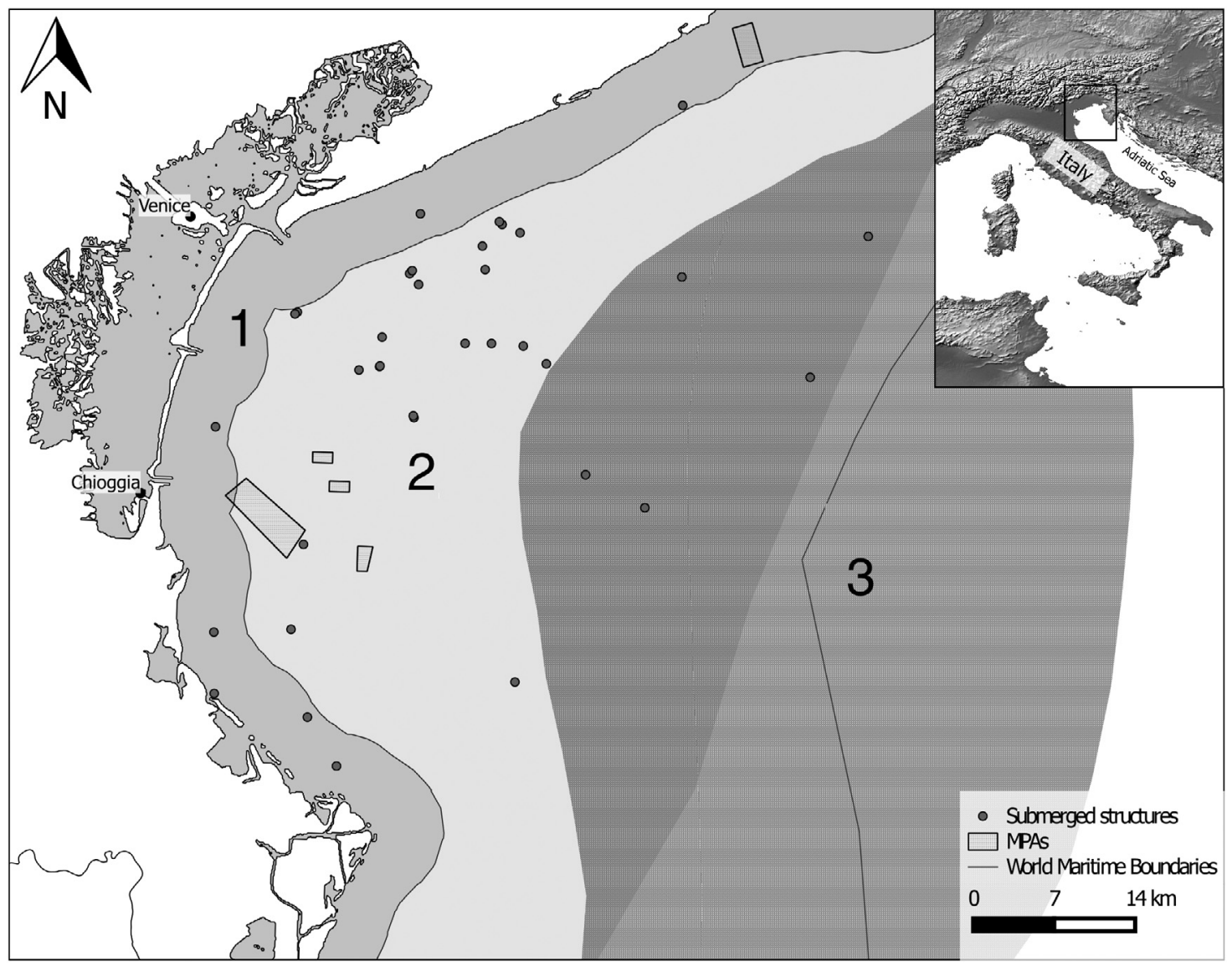

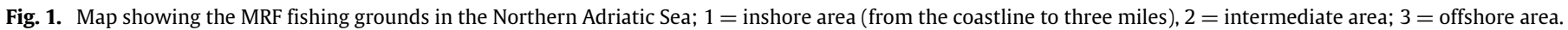

According to these questionnaires, three fishing techniques are adopted in the study area by anglers. These are Bolentino (a line provided with 2 hooks and wrapped around a cork), drifting and rod in the order (49\%, $31 \%$ and $20 \%$ of preferences, respectively).

More than $50 \%$ of anglers usually fish in the in-shore area, within three miles from the coastline. If present, they preferentially exploit areas in proximity of submerged structures, principally represented by mussel culture farms, but also by wrecks and rocky reefs (locally called tegnue). This is due to the fact that they mainly target demersal species, which in these zones captures are generally more abundant and of bigger size (see also Fig. 1). Anglers targeting for pelagic fish, on the contrary, explore offshore areas (Fig. 1, Table 1).

In relation to the target species, collected data showed a wide spectrum composed by 29 exploited species, mainly fish, but also cephalopods (Table 1). Considering the CPUE values, five of them, bluefin tuna, common dolphinfish, cuttlefish, gilt-headed seabream and little tunny, in the order, account for about $60 \%$ (Table 1).

On the basis of collected data (about 55\% of interviewed declared 3 trips per month or more), an average of 30 fishing trips per year per boat was estimated. Summer and Fall are the favourite fishing seasons (30\% and 35\% respectively), and during these two seasons, the frequency of the fishing trips increases to almost 2 per week.

Combining collected data (CPUE, average trips per year and angler preferences) with the estimates of the total number of anglers in the region (according to the different sources, FIPSAS or MIPAAF), the value of total captures per year ranged between 287 and 465 tons, respectively. Of this, the first five species (gilthead seabream, cuttlefish, Atlantic bluefin tuna, common dolphinfish,
European squid and Atlantic mackerel, in the order) account for more than $73 \%$ (Table 1 ).

Collected data offered also the opportunity for a very preliminary economic estimate. About $70 \%$ of the interviewed declared, on average, a cost of about $50 €$ or less per trip, with the rest declaring more than $100 €$, and up to $600 €$ per trip in the case of the bluefin tuna angling.

In Table 2, a comparison with official statistics from commercial fishery is reported. Considering regional data (MIPAAF, 2014), the catch of Atlantic mackerel and common pandora by MRF resulted higher than commercial landings. In order to enlarge the dataset and to use the same reference year (2014), data have been compared with those from the Chioggia fish market, the largest in the Northern Adriatic Sea. In this case, the number of species for which captures by MRF exceed the commercial ones increased to six, with bluefish, bonito, pandora and picarel showing values one order of magnitude larger Table 2.

In relation to possible ecological effects, the analysis of the Primary Production Required to sustain catches showed a value of $10 \%$ and $16 \%$, depending on the estimate of the anglers number; accordingly, the Lindex varied between 0.012 and 0.020 , with a probability to be sustainably fished of 0.95 and 0.74 , respectively (see Table 3).

\section{Discussion}

Marine recreational fishing (MRF) is recognized to play an important role not only in social but also in environmental terms and there is an increasing scientific interest about it. Even if it is often considered negligible in terms of contribution to the biomass extraction in comparison with commercial fisheries, an important 
Table 1

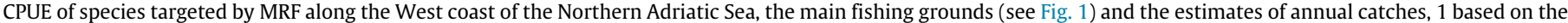
angler's number in the area reported by FIPSAS (1624); 2 based on the angler's number in the area reported by MIPAAF (2633).

\begin{tabular}{|c|c|c|c|c|c|c|c|c|c|c|c|}
\hline \multirow[t]{2}{*}{ Species } & & \multirow[t]{2}{*}{ Fishing ground } & \multicolumn{3}{|c|}{ CPUE $\left(\mathrm{kg}_{\text {p person }} \mathrm{y}^{-1}\right)$} & \multicolumn{3}{|c|}{ Annual catches 1 (tons) } & \multicolumn{3}{|c|}{ Annual catches 2 (tons) } \\
\hline & & & 1st Qu. & Median & 3rd Qu. & 1st Qu. & Median & 3rd Qu. & 1st Qu. & Median & 3rd Qu. \\
\hline Gilthead seabream & Sparus aurata & 1 & 56.6 & 67.2 & 76.9 & 53.3 & 63.3 & 72.5 & 86.3 & 102.6 & 117.5 \\
\hline Cuttlefish & Sepia officinalis & 1 & 64.2 & 73.0 & 82.6 & 45.9 & 52.1 & 59.1 & 74.4 & 84.5 & 95.7 \\
\hline Atlantic bluefin tuna & Thunnus thynnus & 3 & 94.4 & 110.7 & 129.8 & 30.7 & 36.0 & 42.2 & 49.7 & 58.3 & 68.3 \\
\hline Common dolphinfish & Coryphaena hippurus & $1-2$ & 80.0 & 87.8 & 96.1 & 26.0 & 28.5 & 31.2 & 42.1 & 46.2 & 50.6 \\
\hline Atlantic mackerel & Scomber scombrus & 2 & 27.8 & 31.6 & 35.9 & 18.9 & 21.5 & 24.5 & 30.7 & 34.9 & 39.7 \\
\hline European squid & Loligo vulgaris & 2 & 32.9 & 40.3 & 49.5 & 12.8 & 15.7 & 19.3 & 20.8 & 25.5 & 31.3 \\
\hline European seabass & Dicentrarchus labrax & 1 & 20.1 & 23.2 & 26.5 & 8.5 & 9.8 & 11.2 & 13.8 & 15.9 & 18.2 \\
\hline Little tunny & Euthynnus alletteratus & $2-3$ & 48.7 & 59.7 & 70 & 7.9 & 9.7 & 11.4 & 12.8 & 15.7 & 18.4 \\
\hline $\begin{array}{l}\text { Atlantic horse } \\
\text { mackerel }\end{array}$ & Trachurus trachurus & 2 & 15.0 & 17.8 & 21.2 & 5.3 & 6.3 & 7.6 & 8.7 & 10.3 & 12.3 \\
\hline Leerfish & Lichia amia & 1 & 22.6 & 28.2 & 34.8 & 4.4 & 5.5 & 6.8 & 7.1 & 8.9 & 11 \\
\hline Bluefish & Pomatomus saltatrix & $1-2$ & 14.7 & 17.4 & 20.1 & 3.8 & 4.5 & 5.2 & 6.2 & 7.3 & 8.5 \\
\hline Sand steenbras & Lithognathus mormyrus & 1 & 8.0 & 9.1 & 10.4 & 3.9 & 4.5 & 5.1 & 6.3 & 7.2 & 8.3 \\
\hline Bogue & Boops boops & 1 & 13.9 & 15.8 & 18 & 3.6 & 4.1 & 4.7 & 5.9 & 6.7 & 7.6 \\
\hline White seabream & Diplodus sargus sargus & 1 & 19.9 & 26.8 & 32.7 & 2.6 & 3.5 & 4.3 & 4.2 & 5.6 & 6.9 \\
\hline Atlantic bonito & Sarda sarda & $1-2-3$ & 10.4 & 12.5 & 14.3 & 2.7 & 3.3 & 3.7 & 4.4 & 5.3 & 6 \\
\hline Common pandora & Pagellus erythrinus & 1 & 7.2 & 8.6 & 10.1 & 2.6 & 3.1 & 3.6 & 4.2 & 5 & 5.9 \\
\hline European hake & Merluccius merluccius & 1 & 8.3 & 10.0 & 12.0 & 2.4 & 2.9 & 3.5 & 4 & 4.8 & 5.7 \\
\hline $\begin{array}{l}\text { Atlantic chub } \\
\text { mackerel }\end{array}$ & Scomber colias & 2 & 17.3 & 27.3 & 33.4 & 1.7 & 2.7 & 3.3 & 2.7 & 4.3 & 5.3 \\
\hline Mullet & Mugil spp. & 1 & 13.3 & 16.6 & 21.0 & 1.7 & 2.2 & 2.7 & 2.8 & 3.5 & 4.4 \\
\hline Whiting & Merlangius merlangus & 1 & 6.4 & 7.6 & 8.8 & 1.5 & 1.7 & 2 & 2.4 & 2.8 & 3.3 \\
\hline European eel & Anguilla anguilla & 1 & 4.9 & 6.3 & 8.0 & 1.1 & 1.4 & 1.8 & 1.8 & 2.3 & 3 \\
\hline Blue shark & Prionace glauca & $1-2$ & 4.7 & 5.9 & 7.1 & 0.8 & 1 & 1.2 & 1.2 & 1.6 & 1.9 \\
\hline Picarel & Spicara maena & 1 & 4.3 & 5.1 & 6.0 & 0.7 & 0.8 & 1 & 1.1 & 1.4 & 1.6 \\
\hline Tub gurnard & Chelidonichthys lucerna & 1 & 3.2 & 4.3 & 5.1 & 0.5 & 0.7 & 0.8 & 0.8 & 1.1 & 1.4 \\
\hline Saddled seabream & Oblada melanura & 1 & 5.0 & 5.8 & 6.5 & 0.5 & 0.6 & 0.6 & 0.8 & 0.9 & 1 \\
\hline Ray & Raja spp. & 1 & 3.4 & 4.1 & 4.7 & 0.4 & 0.5 & 0.6 & 0.7 & 0.9 & 1 \\
\hline European flounder & Platichthys flesus & 1 & 3.5 & 4.9 & 6.5 & 0.3 & 0.5 & 0.6 & 0.5 & 0.8 & 1 \\
\hline Shi drum & Ombrina cirrosa & 1 & 1.9 & 2.3 & 2.7 & 0.3 & 0.3 & 0.4 & 0.4 & 0.5 & 0.6 \\
\hline Turbot & $\begin{array}{l}\text { Scophthalmus } \\
\text { rhombus/maximus }\end{array}$ & 1 & 1.2 & 1.5 & 1.7 & 0.2 & 0.2 & 0.2 & 0.3 & 0.3 & 0.4 \\
\hline
\end{tabular}

Table 2

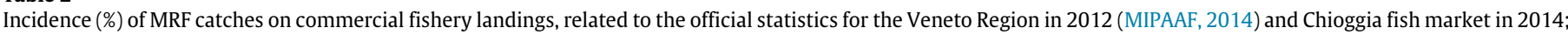
results for the estimates based on two different angler's number in the area (FIPSAS $=1624$, MIPAAF $=2633$ ) are reported.

\begin{tabular}{|c|c|c|c|c|c|}
\hline \multirow[t]{2}{*}{ Species } & & \multicolumn{2}{|c|}{ Veneto Region (2012) } & \multicolumn{2}{|c|}{ Chioggia fish market (2014) } \\
\hline & & FIPSAS & MIPAAF & FIPSAS & MIPAAF \\
\hline Gilthead seabream & Sparus aurata & n.a. & n.a. & 66.3 & 107.5 \\
\hline Common cuttlefish & Sepia officinalis & 5.1 & 8.2 & 6.8 & 11.0 \\
\hline Common dolphinfish & Coryphaena hippurus & 38.0 & 61.6 & n.a. & n.a. \\
\hline Atlantic mackerel & Scomber scombrus & 165.4 & 268.5 & 159.8 & 259.4 \\
\hline European squid & Loligo vulgaris & 7.9 & 12.8 & 42.0 & 68.2 \\
\hline European seabass & Dicentrarchus labrax & n.a. & n.a. & 30.7 & 49.9 \\
\hline Atlantic horse mackerel & Trachurus trachurus & 4.1 & 6.7 & 9.8 & 16.0 \\
\hline Leerfish & Lichia amia & n.a. & n.a. & 37.7 & 60.9 \\
\hline Bluefish & Pomatomus saltatrix & n.a. & n.a. & 771.5 & 1251.5 \\
\hline Sand steenbras & Lithognathus mormyrus & n.a. & n.a. & 139.9 & 223.8 \\
\hline Bogue & Boops boops & 31.5 & 51.5 & 104.3 & 170.4 \\
\hline White seabream & Diplodus sargus sargus & n.a. & n.a. & 30.8 & 49.2 \\
\hline Atlantic bonito & Sarda sarda & n.a. & n.a. & 1301.3 & 2089.9 \\
\hline Common pandora & Pagellus erythrinus & 310.0 & 500.0 & 1260.7 & 2033.3 \\
\hline European hake & Merluccius merluccius & 11.6 & 19.2 & 8.8 & 14.6 \\
\hline Atlantic chub mackerel & Scomber colias & 20.8 & 33.1 & n.a. & n.a. \\
\hline Mullet & Mugil spp. & 0.2 & 0.3 & 0.2 & 0.3 \\
\hline Whiting & Merlangius merlangus & 0.3 & 0.4 & 1.4 & 2.2 \\
\hline European eel & Anguilla anguilla & n.a. & n.a. & 42.0 & 68.9 \\
\hline Blue shark & Prionace glauca & 1.0 & 1.6 & n.a. & n.a. \\
\hline Picarel & Spicara maena & n.a. & n.a. & 620.2 & 1085.3 \\
\hline Tub gurnard & Chelidonichthys lucerna & n.a. & n.a. & 14.0 & 22.0 \\
\hline Ray & Raja spp. & 8.3 & 15.0 & 11.2 & 20.1 \\
\hline European flounder & Platichthys flesus & n.a. & n.a. & 9.3 & 14.9 \\
\hline Shi drum & Ombrina cirrosa & n.a. & n.a. & 35.4 & 59.0 \\
\hline Turbot & Scophthalmus rhombus/maximus & 0.3 & 0.5 & 0.6 & 0.9 \\
\hline
\end{tabular}

contribution for some species has been recently demonstrated Strehlow et al. (2012).

The present study analysed the MRF on the Western coast of the North Adriatic Sea, aiming to describe the state of the art and to preliminary assess catches, in comparison with the commercial ones, at the regional scale. In the area, the MRF is deeply rooted in the local population that exploits local geographic conditions, which allow an easy access to the sea, in relation to the presence of sandy beaches, lagoons and moorings. Moreover, anglers use to fish not only by boat, but also by concrete structures such as 
Table 3

Trophodynamic indicators values, calculated on total annual catches, based on two different angler's number in the area (FIPSAS $=1624$, MIPAAF $=2633$ ); values for the scenarios combining MRF and small scale fishery (SSF) in the area are also reported.

\begin{tabular}{lcclc}
\hline & FIPSAS & MIPAAF & FIPSAS + SSF & MIPAAF + SSF \\
\hline PPR\% & 10.11 & 16.4 & 26.45 & 32.73 \\
Lindex & 0.012 & 0.02 & 0.061 & 0.07 \\
psust & 0.94 & 0.75 & 0.34 & 0.27 \\
\hline
\end{tabular}

the inlets of the lagoon and beach groins. The main problem in monitoring this activity is that it is widespread along the entire coast, with many different access points (moorings, but also small private harbours). Furthermore, there is no obligation to notify the authorities the entity of the catches nor to declare the number of trips. Finally, another important challenge is related to the assessment the total number of anglers, as showed by the large variability among the two different sources (Ministry and FIPSAS), used in the present study (previous studies referred an estimate of 0.5-2 millions of anglers for the entire country, OECD, 2011; Tudini, 2011).

For all these reasons, this study was mainly based on an online survey. Therefore, the reliability of the results of this survey was critically reviewed. The response rate for the survey was quite close the acceptable threshold of $25 \%$ (Groves, 2006) and no analysis was carried out to estimate the bias introduced by non-respondents.

In relation to the obtained results, a first evidence of the specificity of the analysed area is offered by the preferences for fishing techniques that resulted completely inverted in terms of ranking, in comparison with data collected in a previous analysis, carried out at the national level (GFCM-SAC, 2010). On the contrary, the estimate of the average number of trips per year was in agreement with the national data (30 and 27 trips per year, respectively), as for the main fishery seasons (GFCM-SAC, 2010). Notwithstanding this, the annual total catch per angler (191 kg) proved significantly higher than the value reported at national level (167 kg) (Cingolani et al., 1999).

Collected data highlighted a wide target spectrum, with 29 exploited species. In general, the list is in agreement with national data (GFCM-SAC, 2010); in terms of preferences, however, bogue, striped sea bream, horse mackerel, sea bream, and mackerel are substituted, as the most popular species, by cuttlefish, squid and European seabass at the regional level, again confirming peculiarities of the analysed area and/or local preferences.

The assessment of catches in quantitative terms highlighted the important role played by MRF, with six species showing values higher than the commercial counterpart at regional level, even considering the conservative estimate. It is worthy to note, however, that at least for pandora and bonito, the lower market price could probably affect the commercial catches values.

According to recently published data about total catches by artisanal fishery along the Venetian coast (about 1000 tons per year) (Pranovi et al., in press), MRF captures amounted to $29 \%$ or $46 \%$ of the commercial ones. All this confirmed that considering as negligible the biomass extracted by anglers from the Western North Adriatic Sea is not a realistic assumption. This is in line with findings for other basins around the world (Lewin et al., 2006; Strehlow et al., 2012) and claims for considering the MRF, together with all other exploitations activities, within the context of integrated management strategies of the coastal area.

Moreover, it has to be considered that MRF targets also species subjected to quotas (as the Atlantic bluefin tuna, capturing 3\%-5\% of the entire Italian quota) or inserted in particular conservation projects (as the European eel).

The high incidence ( $12 \%$ in terms of CPUE) of two non indigenous species, as bluefish (Pomatomus saltatrix) and common dolphinfish (Coriphaena hippurus), on one side confirms the presence of stable populations of these thermophilic species in the study area; on the other it highlights the plasticity of the MRF, able to quickly adapt for exploiting newly established resources, as anglers are not subjected to market rules. Moreover, this suggests that the MRF catches monitoring could represent an effective tool to investigate nekton assemblage modifications, within the context of climate changes. This may prove of great importance in the context of the arrival of new thermophilic species in the Northern Adriatic Sea, which is considered a hotspot for nonindigenous species in the Mediterranean basin (Libralato et al., 2015).

In relation to the assessment of ecological effects of the MRF exploitation, the Primary Production Required to sustain the fishery (PPR) (Pauly and Christensen, 1995) and the Lindex (Libralato et al., 2008) are two indicators able to describe the ecological footprint of fishing activities. In terms of PPR, results are slightly higher than those reported on average for the Mediterranean and Italian seas (15\% and 9\% respectively) (Sherman and Hempel, 2008; de Leo et al., 2014), but in line with recent findings (around 16\%) for the same area, in relation to the artisanal fishery analysis (Pranovi et al., in press). On the contrary, the Lindex showed values significantly lower, reflecting in a high probability to be sustainably fished. All this could be explained with the fact that the exploitation by MRF targets in particular high trophic level species, which have a high energetic cost for the ecosystem (reflected in the PPR values), but with lower effects through the trophic web. It is worth noting that the MRF represents just one of the activities affecting the West coast of the North Adriatic Sea in terms of biomass exportation. A very preliminary assessment carried out taking into the account both MRF and artisanal fishery catches, showed a PPR value higher than $25 \%$, and a Lindex of about 0.6 , with a probability to be sustainably fished reduced to 0.34 .

Finally, in relation to the fishing grounds preferences, the present study highlighted the important role for MRF played by submerged structures, such as wrecks, rocky bottom areas, antierosion barriers and mussel culture farms (MCFs), that, giving a vertical dimension to a flat sea-bottom, prove to be attractive for fish, and consequently for anglers. This could represent an opportunity to be investigated in the future. Indeed, given the availability of anglers to pay for fishing, coastal areas closed to commercial fishery, as the mussel culture farms, could be devoted to the MRF, producing an integrative economic revenue, offering new opportunities within the context coastal area management.

\section{Conclusions}

The marine recreational fishing along the West coast of the Northern Adriatic Sea confirmed the features recorded in other European areas, being widespread among the local population. Collected data emphasize the possible ecological role of the MRF exploitation, being comparable for some species with the one by commercial activity.

Much remains to be done to fully understand the phenomenon, and to understand its implications in the near future; it could be necessary to introduce new systems for monitoring activity of recreational anglers to limit the possible increase of the catches and to minimize the negative effects in the same areas of combined effort of commercial and recreational fishing.

All this suggests that the recreational fishing should be explicitly considered for the implementation of the Ecosystem Management Approach, within the context of an integrated coastal zone planning. The ecosystem approach, indeed, strives to balance diverse societal objectives, by taking into account the knowledge and uncertainties about biotic, abiotic and human components of ecosystems, and their interactions. 


\section{References}

Behrenfeld, M.J., Falkowski, P.G., 1997. A consumer's guide to phytoplankton primary productivity models. Limnol. Oceanogr. 42, 1479-1491.

Cingolani, N., Santojanni, A., Belardinelli, A., Colella, S., Donato, F., Penna, R., Sdogati, C., 1999. Sport Fishery in Eastern Mediterranean (Greece \& Italy): Parameter Estimates, Linkages and Conflict with Professional Fisheries-Italy Section. Final Report to the Commission of the European Communities. EU 96/018: p. 448.

Coleman, F.C., Figueira, W.F., Ueland, J.S., Crowder, L.B., 2004. The impact of United States recreational fisheries on marine fish populations. Science 305, 1958-1960.

Coll, M., Libralato, S., Tudela, S., Palomera, I., Pranovi, F., 2008. Ecosystem overfishing in the ocean. PLoS One 3, e3881.

Cooke, S., Cowx, I.G., 2006. Contrasting recreational and commercial fishing: Searching for common issues to promote unified conservation of fisheries resources and aquatic environments. Biol. Conserv. 128, 93-108.

de Leo, F., Miglietta, P., Pavlinović, S., 2014. Marine ecological footprint of Italian Mediterranean fisheries. Sustainability 6, 7482-7495.

Gaudin, C., De Young, C., 2007. Recreational Fisheries in the Mediterranean Countries: A Review of Existing Legal Frameworks. In: Studies and Reviews. General Fisheries Commission for the Mediterranean, FAO, Rome, No. 81, p. 85.

GFCM-SAC, 2010. Report of the Transversal Workshop on the Monitoring of Recreational Fisheries in the GFCM Area. General Fisheries Commission for the Mediterranean, Rome, Italy: p. 31.

Groves, R.M., 2006. Nonresponse rates and nonresponse bias in household surveys. Public Opin. O. 70, 646-675.

Lee, C.C., Chang, C.P., 2008. Tourism development and economic growth: A closer look at 616 panels. Tour. Manag. 29, 180-192.

Lehtonen, R., Pahkinen, E., 2004. Practical Methods for Design and Analysis of Complex Surveys, second ed. John Wiley \& Sons Ltd., Chichester, West Sussex, p. 349.

Lewin, W.-C., Arlinghaus, R., Mehne, T., 2006. Documented and potential biological impacts of recreational fishing: insights for management and conservation. Rev. Fish. Sci. 14, 305-367.

Libralato, S., Coll, M., Tudela, S., Palomera, I., Pranovi, F., 2008. Novel index for quantification of ecosystem effects of fishing as removal of secondary production. Mar. Ecol. Prog. Ser. 355, 107-129.

Libralato, S., Caccin, A., Pranovi, F., 2015. Modelling species invasions using thermal and trophic niche dynamics under climate change. Front. Mar. Sci. http://dx.doi.org/10.3389/fmars.2015.00029.
MIPAAF, 2014. Rapporto Annuale 2012. Strutture produttive, andamento pesca. Ministero delle Politiche Agricole, Alimentari e Forestali. Roma.

Moutopoulos, D.K., Katselis, G., Kios, K., Tsotskou, A., Tsikliras, A.C., Stergiou, K.I., 2013. Estimation and reconstruction of shore-based recreational angling fisheries catches in the Greek Seas (1950-2010). J. Biol. Res.-Thessalon 20, 376-381.

OECD, 2011. OECD Review of Fisheries 2011 Policies and Summary Statistics. OECD Italy. Paris, pp. 299-308 (Chapter 15).

Pauly, D., Christensen, V., 1995. Primary production required to sustain global fisheries. Nature 374, 255-257.

Pawson, M.G., Glenn, H., Padda, G., 2008. The definition of marine recreational fishing in Europe. Mar. Policy 32, 339-350.

Pranovi, F., Anelli Monti, M., Caccin, A., Brigolin, D., Zucchetta, M., 2015. Permanent trawl fishery closures in the Mediterranean Sea: an effective management strategy? Mar. Policy 60, 272-279.

Pranovi, F., Colla, S., Valeri, P., Anelli Monti, M., 2015. Present and future of the artisanal fishery along Venetian coasts (Western Mediterranean Sea). Ocean Coast. Manage. (in press).

Romanelli, M., Fiori, F., 2013. Censimento della pesca marittima ricreativa ai sensi del D.M. 06.12.2010 MIPAAF: analisi dei dati. Biol. Mar. Mediterr. 20, 202-203.

Shao, J., Tu, D., 1996. The Jackknife and Bootstrap. Corr. 2nd priniting. Springer, New York, p. 516.

Sherman, K., Hempel, G., 2008. The UNEP Large Marine Ecosystem Report: A Perspective on Changing Conditions in LMEs of the World's Regional Seas. In: UNEP Regional Seas Reports and Studies. No. 182, United Nations Environment Programme, Nairobi, Kenya.

Silvestri, R., 2013. Stato dell'arte della pesca ricreativa in Italia. Not. SIBM 63, 23-29.

Strehlow, H.V., Schultz, N., Zimmermann, C., Hammer, C., 2012. Cod catches taken by the German recreational fishery in the Western Baltic Sea, 2005-2010: implications for stock assessment and management. ICES J. Mar. Sci. 69, $1769-1780$

Sutinen, J.G., Johnston, R.J., 2003. Angling management organizations: integrating the recreational sector into fishery management. Mar. Policy 27, 471-487.

Tudini, L., 2011. Recreational marine fisheries in the framework of fish resource management. In: Cataudella, S., Spagnolo, M. (Eds.), The State of Italian Marine Fisheries and Aquaculture. Ministry of Agriculture and Forestry, Rome pp. 406-408. 